\title{
Optimized Solar Energy Power Supply for Remote Wireless Sensors Based on IEEE 802.15.4 Standard
}

\author{
Ondrej Krejcar ${ }^{1}$ and Miroslav Mahdal ${ }^{2}$ \\ ${ }^{1}$ Department of Information Technologies, Faculty of Informatics and Management, University of Hradec Kralove, \\ Rokitanskeho 62, 50003 Hradec Kralove, Czech Republic \\ ${ }^{2}$ Department of Control Systems and Instrumentation, Faculty of Mechanical Engineering, VSB Technical University of Ostrava, \\ 17. Listopadu 15, 70833 Ostrava, Czech Republic
}

Correspondence should be addressed to Ondrej Krejcar, ondrej.krejcar@remoteworld.net

Received 11 September 2012; Accepted 20 November 2012

Academic Editor: Manolis Souliotis

Copyright (C) 2012 O. Krejcar and M. Mahdal. This is an open access article distributed under the Creative Commons Attribution License, which permits unrestricted use, distribution, and reproduction in any medium, provided the original work is properly cited.

\begin{abstract}
Powering of intelligent wireless sensors without a permanent electric connection is a general problem which is often solved by adopting alternative power sources. One of the most commonly used sources is solar energy in the form of solar panel and charging circuits. However, it is not possible to find a solution in the markets for operation in changeable weather conditions, where sun intensity is not so high. This fact leads us to the development of optimized solar panel and all circuits for reliable power supply of wireless sensors. A special charging circuit for Li-ION battery and DC-DC adapter circuit for stabilization of wireless sensor working voltage were developed and optimized for very low energy consumption and high efficiency.
\end{abstract}

\section{Introduction}

Wireless sensors are currently largely used for measurement of different variables (temperature, lighting humidity, etc.) [1]. These sensors are often placed in an outdoor environments without electricity connection. In those cases, it is suitable to power wireless sensors by alternative power supply. There are several existing alternative power sources. However, wind energy is not suitable for powering wireless modules of compact size due to mechanical and size issues as wells as for its unsuitability in cities agglomerations [2]. In addition to problems with wind energy, water energy is problematic for localization of sensors or the water sources.

These power sources are able to supply large amounts of energy, up to tens of MW. For example, the wing turbine rotor blades with a diameter of 100 meters can deliver up to $3 \mathrm{MW}$ power, wind power plant, see in Pchery [3]. Such performance, respectively, such current is very difficult to adjust to power wireless embedded systems regarding to the needs of power management, safety issues, and intervention in a system. Besides these sources there also exist power sources for wireless-embedded systems which are far more appropriate. It is energy harvesting from sources based on the principle of piezoelectric, vibration, thermal, acoustic, or solar. From the selection of named sources, it is the solar power energy which is the most suitable in terms of power density and power wireless sensors. This statement illustrates the article [4] in which the authors compare alternative technologies of power source according to power density in watts per $\mathrm{cm}^{3}$. The solar cells energy density generated about $\mathrm{mW} / \mathrm{cm}^{3}$, compared to the other sources such as piezoelectric, vibration, thermoelectric, or acoustic which supplied $\mu \mathrm{W} / \mathrm{cm}^{3}$.

There are several standards for wireless sensors, where IEEE 802.15.4 is the most suitable for its low power consumption as well as for the option of going to sleep state mode. This fact exemplifies the article [5] which deals with sensor networks based on IEEE 802.15.4 standard and their applications to the wine environment (measurement of conditions for wine growing). It confirms the suitability of this standard in combination with alternative power source and usage for occasional data sending. The frequency of data sending can be twice per day, and for the rest of the time the wireless module is in state of reduced power consumption. 
Power consumption of these devices for transmit mode is by default $120 \mathrm{~mA}$. Receiving mode absorbs from 30 to $70 \mathrm{~mA}$, while in sleep mode it changes to $2.6 \mu \mathrm{A}[6]$.

Based on the previous, part it is possible to operate wireless sensors for a long time in a condition of optimal design of circuits for charging, battery, and converter [7].

\section{Problem Definition}

Air pollution presents a serious problem for some industrial cities around the world. Unfortunately, this applies even to certain European cities, 2 where large concentration of very dangerous pollution is still present. One of the most polluted cities in EU is Ostrava in the Czech Republic. This industrial city has a population of almost 300 thousand people who live in some cases inside or among the factories, such as Arcelor Mittal Steel, or Vitkovice. Therefore, the monitoring of the current state of environment quality is strongly needed. Due to the fact that the city agglomeration occupies area without any mountains with mostly windy weather, high number of remote sensor stations is required to monitor such vast area.

The aim is to develop a complex smart sensor with communication interface that will be able to communicate with other nodes in the network and transmit data to the operator station. It is necessary to supply such sensors with complex alternative power source system which still needs to be developed and tested. There is also a request to have a lowcost solution to allow a measurement from as many places as possible. Developed power system must contain only lowcost components which together with the wireless module will provide a cheap and reliable solution including high efficiency. The third requirement is the independence from the power supply and the ability to have a functional battery charging circuit at low-light conditions, where the solar panel usage is expected.

\section{Related Work}

The cases of intelligent sensors with alternative power supply are well known, and these autonomous units can be found in several publications. The article [5] uses MPWiNodeZ unit with the currently outdated ZigBee wireless module (JN5121). The described solution uses the power management unit which includes a DC-DC converter and a direct Ni-MH batteries charging. Wireless module JN5121 provides the selection for measurements and for switching of input alternative source. This solution is advantageous in its design simplicity and usage of the wireless module for switching and selection of an input alternative source, the activation of sensors, and so forth. However, the solution is for our purposes of optimized power supply inadequate in terms of constant power supply of input DC-DC converters. By placing the wireless module into the sleep mode, it is not possible to identify the value of the battery voltage on the input power supply or also to effect of the battery charging. A sleep period is necessary to be chosen according to these facts.

Another solution [8] uses, except Li-ION battery charging, also the possibility to charge a supercapacity which expressively extends the life work of wireless module without the input of power supply source. Another advantage is the ability to switch source, that is, it can be switched on the battery source at energy exhaustion from supercapacity. This solution has substantially larger dimensions, and as well as a in the solution of the article [7], the used solar panels have low output voltage, DC-DC converters in a chip as the MAX1795, battery charging circuits with regulation of output voltage (MAX1811 circuit), switching circuits, and other control parts. These facts led us to create our own solar panel compound of solar cuts, charging circuit that would be able to work in low output voltage of the solar panel and provide the possibility to charge any kind of battery, including the design of the DC-DC converter with high efficiency. The solution that we created uses our designed charging circuit composed of discrete components on whose output LOW RDSON MOSFET transistor is added. Due to low losses related to this member, we can choose a solar cell with a lower output voltage, and similarly due to very simple change of resistance $R 6$ which will alternate the value of the output voltage, we are able to charge any kind of a battery within this setting (Figure 3). Designed charging circuit works as a regulator and does not need for its activities other circuits as the wireless module which would control the charging. Subsequently, the end member (wireless module) may be put into a mode with reduced consumption for a specified time without overcharging the battery. DC-DC converter which stabilizes the input variables voltage in range from $3.2 \mathrm{~V}$ to $4.2 \mathrm{~V}$ to value $3 \mathrm{~V}$ was designed to power wireless module JN5139 from the battery. Circuit NCP3063 from ON Semiconductor Company supplemented with MOSFET transistor type $\mathrm{P}$ is the converter foundation. By using this solution, we have achieved higher efficiency than standard stabilizers like Zener diode, and we have established that this efficiency is compensated in terms of circuits such as LTC3531-3 from Linear Technology. The whole power supply device with the wireless module shows a good stability and ability to work in conditions with reduced light intensity.

The rest of this paper deals with a complex optimal solution of electronic unit which can be used with solar panel for a long-time operation of intelligent wireless sensor modules. First part (Section 4) discusses the development of suitable solar panel. Next part (Section 6) provides details about the design of charging circuit including the simulation and real measurement in comparison to existing solutions. Finally, the development of suitable converter is described (Section 7) as well as complete final solution of power part.

\section{Solar Panel Development}

Due to the development of the whole solution of powering wireless sensors, we need to develop our own solar panel which will be the final part of the whole solution. Used solar cells with type mark SC22-16A are of small sizes $(51.2 \mathrm{~mm} \times 13 \mathrm{~mm})$, where the voltage of one solar cell is $0.57 \mathrm{~V}$ at full lighting of the cell. One solar cell has a defined short-circuit current of $180 \mathrm{~mA}$. These values are given by SOLARTEC Ltd. manufacturer for standard test 
conditions of $1000 \mathrm{~W} / \mathrm{m}^{2}$ with terrestrial spectra of AM $1.5 \mathrm{G}$ at temperature $25^{\circ} \mathrm{C}$. The whole solar panel is composed of 10 solar cells with the mentioned parameters arranged in series with total supplying voltage of approximately $5.7 \mathrm{~V}$ and maximum current $180 \mathrm{~mA}$ at full lighting (Figure 9). If necessary, it is possible to add more solar cells to the solar panel for an increasing value of the output voltage.

\section{Selection of Rechargeable Battery}

Selection of a suitable type of the battery has to be determined on the base of working conditions of the sensors. Energy demand of current intelligent sensors is relatively low (for power supply from the electrical power network), but also relatively high in terms of the long-time operation in an outside environment. Tested modules with IEEE 802.15.4 communication interface with the type mark M02 (modules fitted with SMA antenna connector) need a minimum power supply voltage of $2.7 \mathrm{~V}$. Power consumption is up to $120 \mathrm{~mA}$ at transmission and $50 \mathrm{~mA}$ at the receiving mode. Sensors working in the outside conditions need to be designed for temperature range of $-20^{\circ} \mathrm{C} \sim 40^{\circ} \mathrm{C}$. Due to the parameters such as size, weight, or density, the best suitable type is lithium-based battery. Li-ION battery has a typical operating voltage of $3.7 \mathrm{~V}$, low weight, high energy density per $\mathrm{kg}$, and a very good working temperature range. For our purposes, the Li-ION TrustFire protected battery, type 14500 with a capacity of $900 \mathrm{mAh}$ has been used. The particular advantages for us are related to the higher operating voltage that is required to power of wireless module JN5139.

\section{Circuit for Li-ION Battery Charging}

Currently, available commercial products for battery charging provide solutions which are in some cases of cloudy weather (insufficient sun light), very limited. This problem can result in a failure in measurement in case of remote sensors application. This fact leads to the development of new more efficient solution.

In order to use rechargeable lithium batteries, it was necessary to develop a reliable circuit for their charging. A reliable circuit NCP1800 from ON Semiconductor Company was selected at the beginning. In the laboratory conditions everything worked smoothly, but the situation changed after attaching the solar panel. The problem was in the frequent fluctuations of power supply voltage depending on the sunlight. This problem is not yet covered by any manufacturer. Therefore, it was necessary to develop our own circuit which would be resistant to these fluctuations.

6.1. Circuit Development. Most effective processing of solar energy is using direct connection from photovoltaic panel to accumulator battery (Figure 1). However, this option is not suitable for the lifetime of the battery as well as the safety issues. Frequent overcharging dramatically lowers its lifetime (voltage of $4.2 \mathrm{~V}$ is critical), and it increases the explosion hazard.

According to the mentioned reasons, it is necessary to use stabilization of output voltage from solar panel.

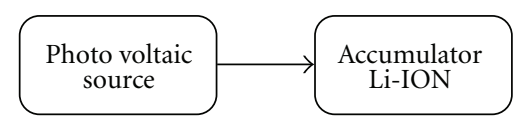

FIGURE 1: Direct connection from photovoltaic panel to accumulator battery.

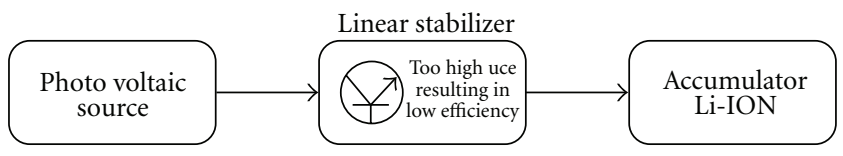

FIgURE 2: Linear stabilization using bipolar transistor.

Regarding circuit modesty, it is the most suitable to use linear stabilization with bipolar transistor (Figure 2). Such solution contains one fundamental disadvantage which is the decreasing of high voltage between collector and emitter Uce.

Another option is using MOSFET transistor. This solution provides certain problems due to the need of a relatively high voltage electrode GATE (app. 4-5V). Due to the different operating principle of MOSFET transistor, the voltage drop is basically missing between the DRAIN electrode and SOURCE. This is very advantageous in terms of efficiency, when the switching element loses a minimum of energy. In order to control the transistor, it was necessary to develop a simple voltage doubler. This drive uses the principle of charge pump. First, differentiating amplifier serves as a source of orthogonal vibrations to charging the output capacitor. When the capacitor is charged, positive voltage is applied to the negative electrode. Both voltages are added, and then the output value is almost twice the amount in comparison to the input voltage (Figure 3 ). This increased voltage drives the second differentiating amplifier which works as a voltage follower and stabilizer of output voltage. Output voltage can be adjusted over a wide range as well as it is possible to choose between the time of battery powering and battery life.

The circuit can be divided into two functional units. The first part represented by $R 1, R 2, R 3, R 4, C 1, C 2, D 2, D 3$, and $U 1$ elements that form the charge-pump circuit, it is the circuit that increases input voltage to almost twice its original value. The second part is a controller that regulates the voltage on the rechargeable battery ( $C 5$ represents the rechargeable battery) so it does not exceed the defined limit. This is important for Lithium batteries which are very sensitive to overcharging. Exceeding the value by only few tens of $\mathrm{mV}$ significantly reduces the lifetime of this cell and can lead to destructive changes.

The regulator (limiting the voltage on the battery) uses switching MOSFET transistor $\mathrm{N}$ instead of an actuator. It would be possible to use regular PNP bipolar type, but it has one major disadvantage. Bipolar types have a characteristic voltage drop $U_{\mathrm{CE}}$ around $1.5 \mathrm{~V}$. Taking into account that the maximum charging voltage of Li-ION battery is $4.2 \mathrm{~V}$, we establish that the power supply voltage must be at least $5.7 \mathrm{~V}$. Another problem is the fact that solar panels provide nominal supply voltage only at a defined minimum 


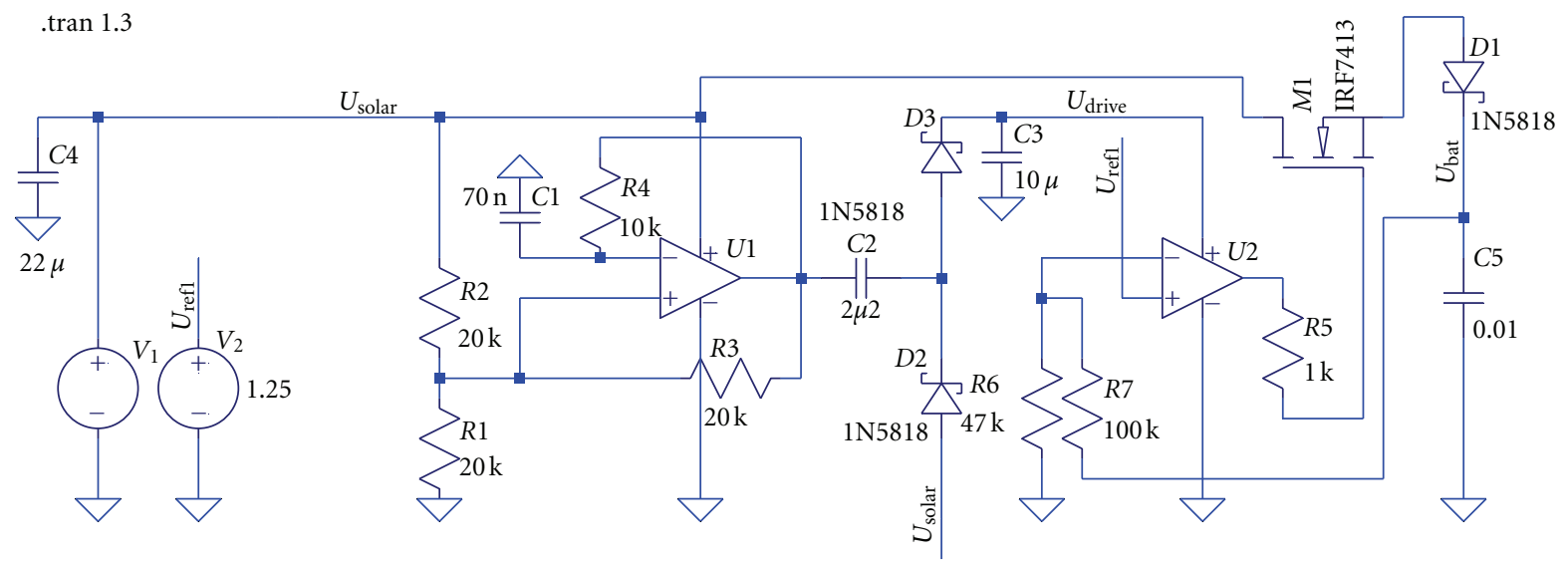

FIGURE 3: Scheme of charging circuit for Li-ION rechargeable battery.

luminous intensity. So, the number of serially connected solar cells (cuts) would be increased to at least 13 pieces. The effectivity of the circuit using a bipolar transistor would also be essentially lower. Power loss would be equal to.

$$
P_{\mathrm{ZTR}}=I_{\mathrm{NAB}} \cdot U_{\mathrm{CE}}[\mathrm{W}] .
$$

By using a unipolar typ, these problems are eliminated. The voltage drop in the conducting direction can be calculated using the formula:

$$
U_{F}=R_{\mathrm{DSON}} \cdot I_{\mathrm{NAB}}[\mathrm{V}],
$$

where $R_{\mathrm{DSON}}$ is the resistance value of the channel at opened transistor (the order of $\mathrm{m} \Omega$ ). By this, it is possible to use only 10 serially connected solar cells.

The charging circuit is formed by charge pump supplying the necessary voltage for the MOSFET transistor. The pump is composed of circuits and operational amplifiers forming a rectangular signal generator. Voltage drops on individual members are expressed by as follows:

$$
U_{\text {drive }}=U_{\text {SOLAR }}+U_{C 2}+2 \cdot U_{F D 2, D 3}[\mathrm{~V}]
$$

And energy transferred per cycle is expressed as follows:

$$
E=\frac{1}{2} \cdot C \cdot\left(\Delta U_{C 2}\right)^{2}[\mathrm{~J}]
$$

$U_{\text {drive }}$ voltage supplies the second operational amplifier marked U2. It directly controls the switching MOSFET M1 (Figure 3).

Such electronic scheme was modeled in a special software environment LTSpice IV, a product from Liner Technologies Company. The behavior of a created model is simulated to avoid any problems during implementation phase. Simulations are used in many other relevant scientific studies [9-11], where models are simulated in Matlab Simulink software. Due to the fact that our solution covers only electronic parts, it is not needed to create a model in Matlab Simulink environment which is more complex, but using of LTSpice is more specialized for desired purposes.
The mentioned literature [9] contains at (Figure 2) a general classical power management system algorithm which is also used by our proposed solution as in (Figure 3) above.

Simulation in (Figure 4) shows an increasing voltage on solar panel from 0 to $5 \mathrm{~V}$. This maximal value is constant for $0.2 \mathrm{~s}$ and then falls back to 0 . Such process was selected due to the state of maximal output power as well as the state with energy gap. Control voltage $U_{\text {drive }}$ which powers the second operational amplifier also grows above a power supply value (almost double value). Battery voltage and charging current are increasing in time. The whole system even goes to oscillation (in time from 0.3 to $0.4 \mathrm{~s}$ ); therefore, it is important that the system returns back to normal function of voltage stabilizer when the battery voltage increases. Even though the complexity of the whole charging circuit is high, the solution provides good effectivity and reliability in connection with solar panel and various sun light.

6.2. Solving of Unstable Period. Stability of the proposed solution is possible to be improved by adding a block for sensing of input voltage from solar panel which would generate logic signal "charging enable signal." Voltage of solar panel as well as reference voltage will serve as an input. Reference voltage also specifies nonstable area which needs to be avoided (Figure 5).

This nonstable area needs to be experimentally identified. Transient voltage needs to be consequently set as a reference. Output signal needs to block or slack the drive of power MOSFET transistor.

The goal is a charging prevention in case of low-input voltage and a slack of changing in case of sufficient energy (sun light).

6.3. Testing. The developed solution was also tested in a real laboratory environment, where it is possible to prepare needed behavior of sun light (variable intensity of sun in time). Because of the need of a solar panel voltage which has a minimum of $3.8 \mathrm{~V}$, we used a special high power LEDs instead of classical lights (max power of $15 \mathrm{~W}$, real $13.5 \mathrm{~W}$, luminous flux $945 \mathrm{~lm}$ ) which were placed at a distance of $20 \mathrm{~cm}$ from the created solar panel (Figure 6). 


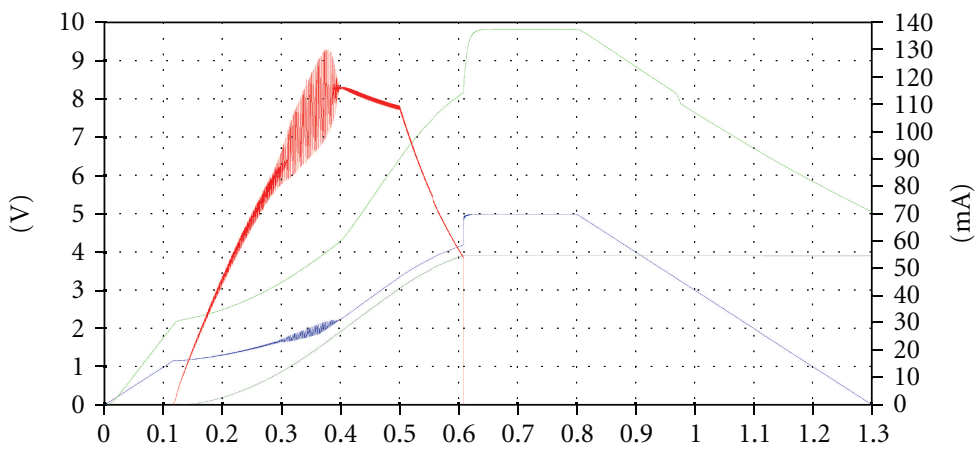

(s)

- Control voltage $U_{\text {drive }}(\mathrm{V})$

- Voltage on the rechargeable battery $(\mathrm{V})$

- Voltage on solar panel (V)

- Battery charging current $(\mathrm{mA})$

FIGURE 4: Simulation of the regulator critical values charging the rechargeable battery from solar cell.

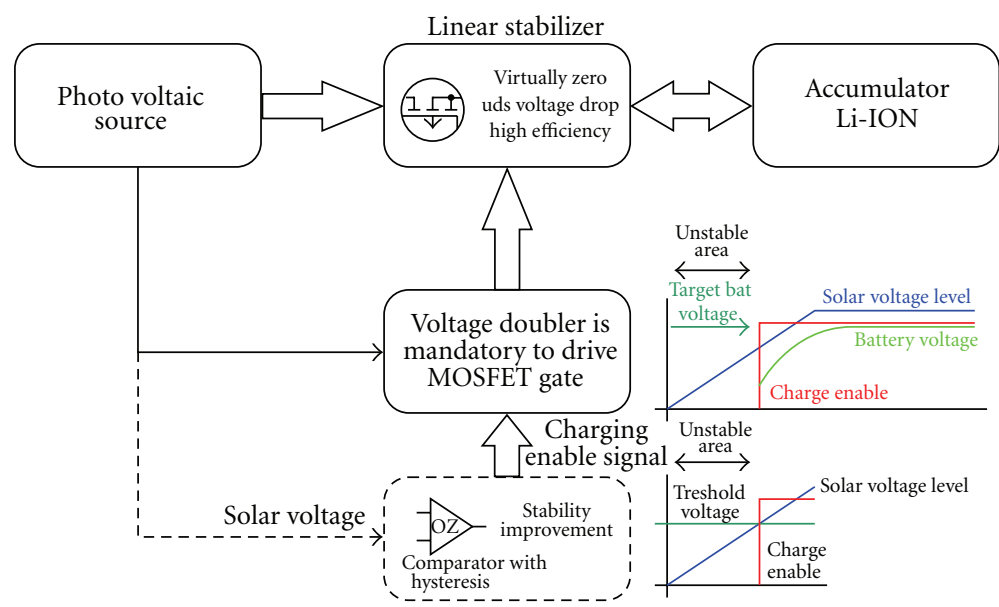

FIGURE 5: The block diagram of the charging circuit with a solution of stability.

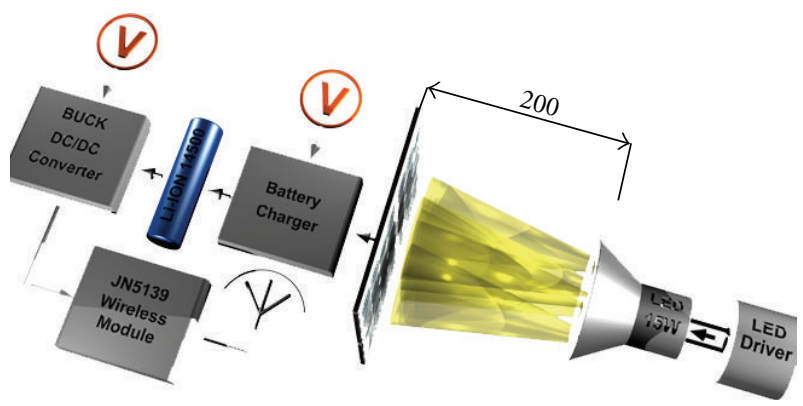

Figure 6: The block diagram of test equipment in the laboratory environment.

In this minimal voltage, a threshold critical power $(2.7 \mathrm{~V})$ of Li-ION battery is exceeded. It also starts the charging. Such sun conditions are normally reached in a real outside environment $[12,13]$.
During the testing phase, at first, the functions of output stabilizer of voltage without connected battery were evaluated (Figure 7). Output power of a light source was increased during the time (from 4 to $22.3 \mathrm{~s}$ ). Voltage on a solar panel increased until it reached maximal value of $4.82 \mathrm{~V}$ (maximal value for our laboratory environment). Output charging voltage is stabilized at $3.78 \mathrm{~V}$ which is equal to working voltage of Li-ION battery, so the created circuit meets the requested function. Commercial charging sources (e.g., LM3685) also satisfy charging purposes; however, they need higher output voltage (typically $4.5 \mathrm{~V}$ ) for correct operation (Figure 7). This fact leads to the request of a higher number of solar panel cells which result in a higher price and finally in a larger dimension of the whole solution.

Further in test phase, we connected several selected batteries of various capacities (Figure 8). Battery charged for $2.65 \mathrm{~h}$ from starting value $3 \mathrm{~V}$ to maximal $3.32 \mathrm{~V}$. Charging current has a value of $110 \mathrm{~mA}$ which decreased in time (voltage increased). 


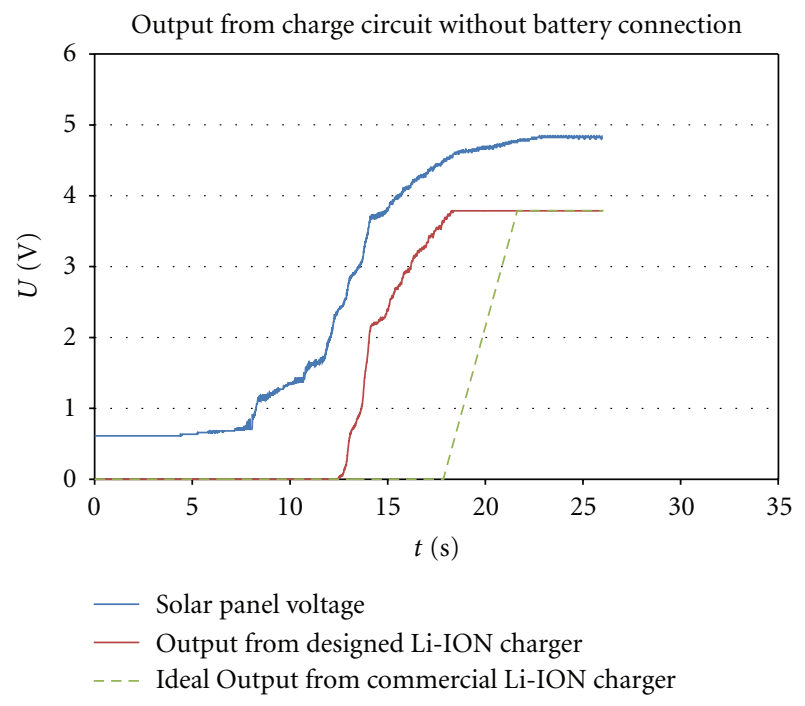

FIGURE 7: Process of voltage on solar panel, designed charging circuit, and ideal commercial solution.

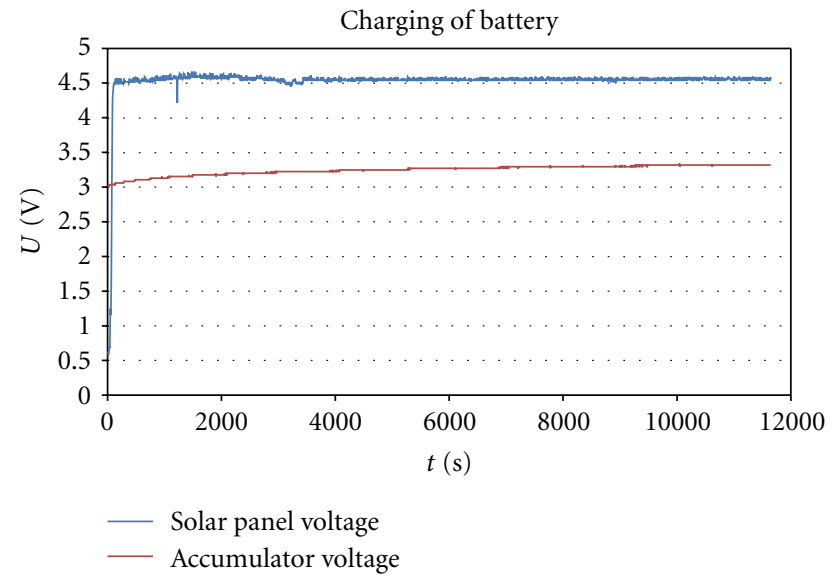

FIGURE 8: Charging of $2600 \mathrm{mAh}$ battery capacity.

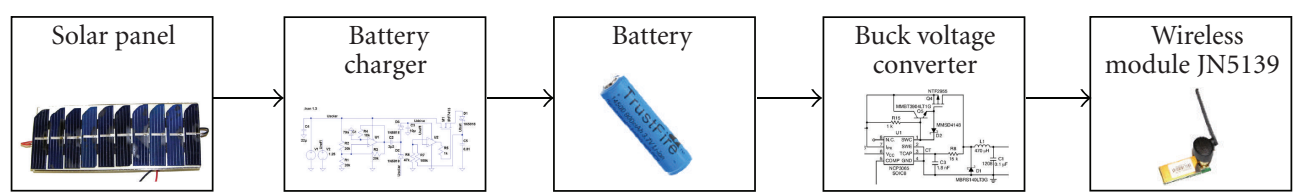

FIGURE 9: Block diagram of the functional unit of alternative power supply source.

\section{Completed Functional Unit of Alternative Power Supply for Wireless Modules}

All components of an alternative power supply source (Figure 9) provided after assembly (without connected wireless module) required functionality. Lowering (Buck) voltage converter was mounted on the input by the switch that turns on or off the converter including the connected wireless module.

Using this, power supply (from converter) can be disconnected in the case of long-term inactivity of wireless module. Before fitting the last part (wireless module) for which the entire device was designed, it is needed to make small adjustments of the module. The wireless module is by default soldered to the printed circuit board with doublesided pins (for easier access to individual pins of the module and the possibility of programming).

The basis of the Buck voltage converter is an integrated circuit NCP3063 from ON Semiconductor Company. This circuit was chosen due to its low cost. It is a monolithic DCDC converter, where the output voltage for wireless module is $3 \mathrm{~V}$. However, we did not use suggested (by manufacturer) 


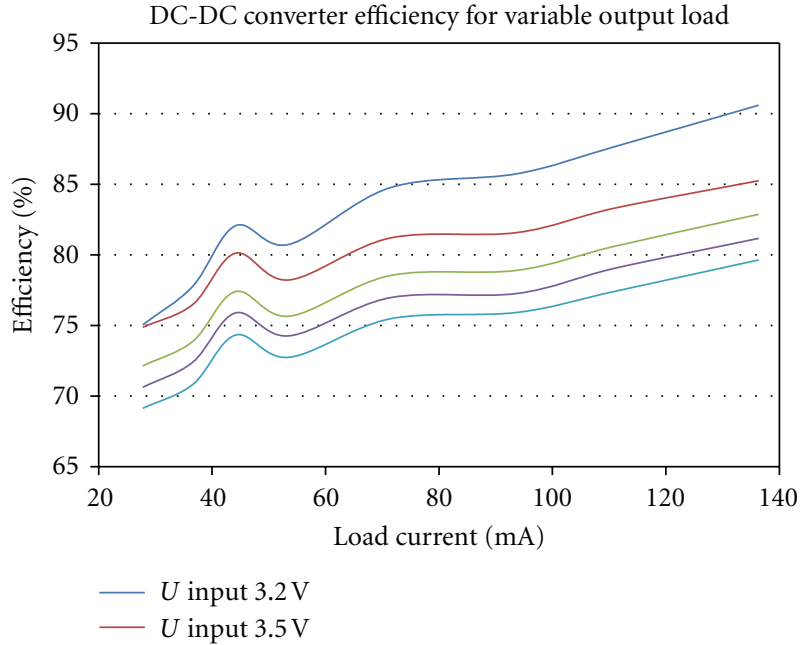

(a)

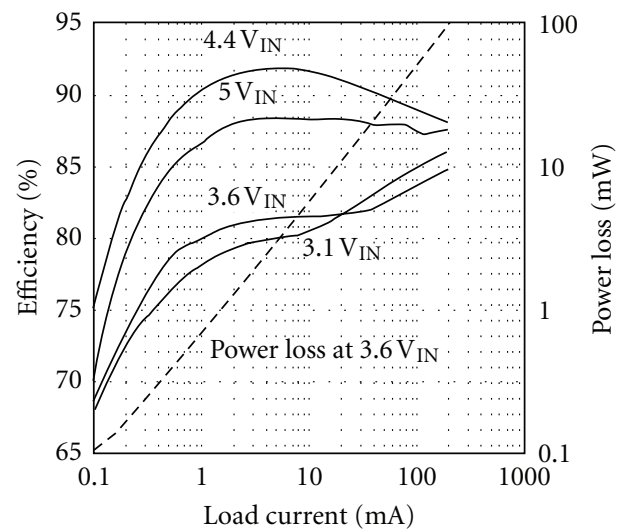

(b)

Figure 10: Comparison of real efficiency of the designed DC-DC converter with NCP3063 (a) with the LTC3531-3 circuit from LT (b) [14].

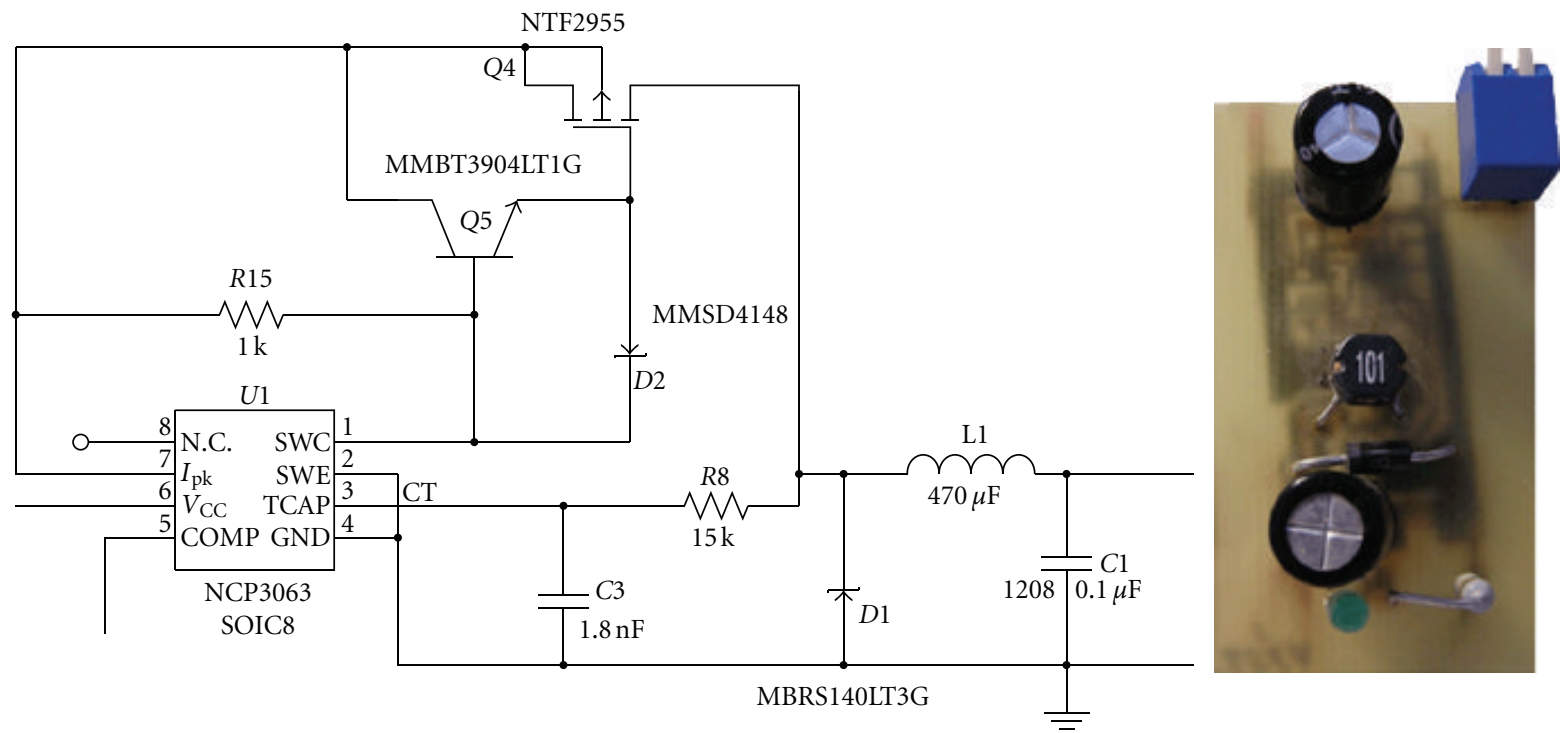

FIGURE 11: Designed DC-DC converter for wireless module power supply.

internal power transistor, but a MOSFET P (Figure 11). This modification resulted in much higher efficiency (70\%-92\%), see (Table 1), instead of a standard stabilizer which uses a Zener diode (efficiency of 25\%-75\%). Our designed circuit is possible to be compared in terms of its efficiency with commercially available DC-DC converters such as circuit LTC3531-3 from Linear Technology; see (Figure 10). The measured values (Figure 10(a)) correspond to the stabilized output voltage of $3 \mathrm{~V}$ at a variable output load and an output current from $30 \mathrm{~mA}$ to $135 \mathrm{~mA}$. The efficiency of the designed converter with MOSFET transistor can be compared to the circuit LTC3531-3 from Linear Technology for Li-ION operating voltage $3.7 \mathrm{~V}$. The efficiency is around $80 \%$.

Such great real efficiency allows a longer operation of wireless sensor module on battery. The advantage is that
TABLE 1: Comparison of various converter types.

\begin{tabular}{lcc}
\hline $\begin{array}{l}\text { Type of circuit } \\
\text { (DC-DC converter) }\end{array}$ & $\begin{array}{c}\text { Efficiency [\%] } \\
\text { (for } U \text { input 3.2 V-4.2 V) }\end{array}$ & $\begin{array}{c}\text { Price } \\
\text { [\$] }\end{array}$ \\
\hline $\begin{array}{l}\text { Designed solution of converter } \\
\text { with NCP3063 circuit and with }\end{array}$ & $70-92$ & 2 \\
$\begin{array}{l}\text { MOS-FET transistor } \\
\text { LTC3531-3 circuit from Linear }\end{array}$ & $80-92$ & 10.5 \\
$\begin{array}{l}\text { Technology } \\
\text { Stabilizer with Zener diode }\end{array}$ & $25-75$ & 0.5 \\
\hline
\end{tabular}

the designed DC-DC converter is offered at especially low price compared to commercial circuit LTC3531-3. The comparison of particular circuits in term of price and efficiency; see (Table 1). 


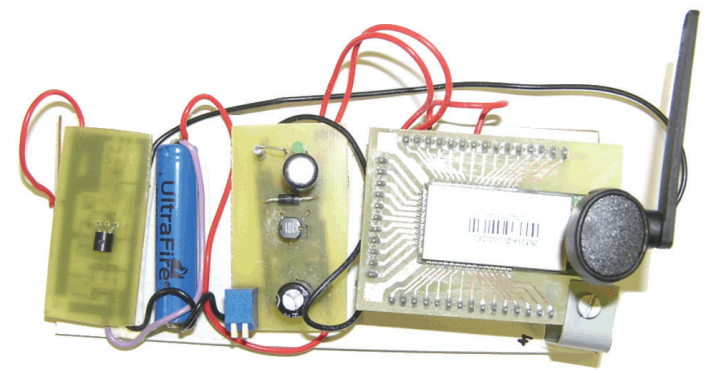

(a)

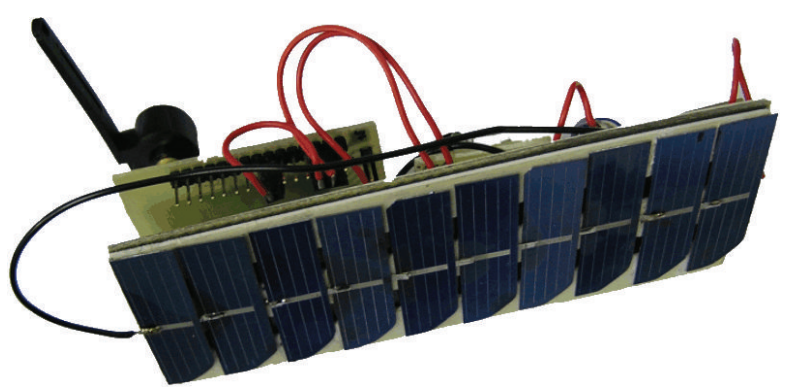

(b)

FIGURE 12: Alternative power supply source for wireless module from side of the solar panel (b) and printed circuit boards (a).
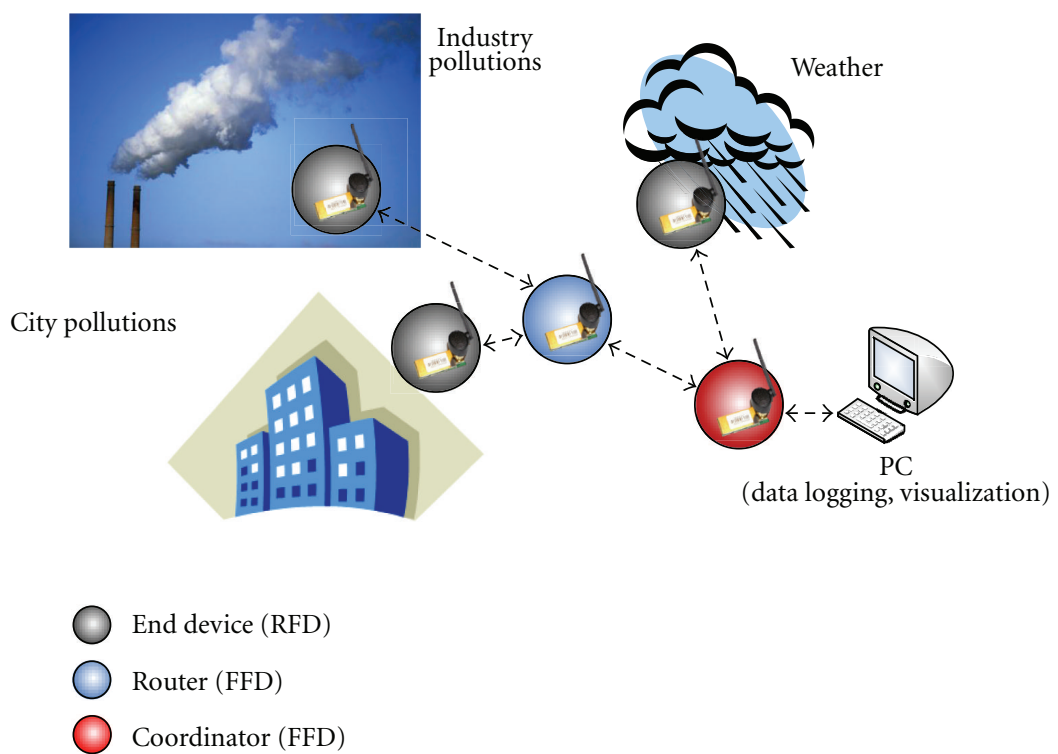

FIGURE 13: Visualization of measurement chain using developed wireless modules.

From (Table 1), the circuit with Zener diode is very cost effective, but it has very low efficiency. The loss of energy is converted into heat in the Zener diode series resistance. Circuit LTC3531-3 has at operating voltage of Li-ION battery $3.7 \mathrm{~V}$ at $100 \mathrm{~mA}$ an output current efficiency of around $82 \%$. The assembled circuit using chip NCP3063 and MOSFET transistor have the same output current efficiency of about $80 \%$. However, the price of this circuit is 5 times cheaper.

The whole view of the assembled alternate power supply source with the wireless module is shown in the (Figure 12).

\section{Developed Solution Use Cases}

As mentioned in the problem definition (Section 2), the complex unit of charging system is designed for measurement of air pollution rate and generally environmental quality inside industrial city (like Ostrava in the Czech Republic). The assumption is that there are several wireless stations of IEEE 802.15.4 standard placed in the monitored area which due to the designed charging unit work completely autonomously. The data are sent from end stations through network structure type three (Figure 13) to the central unit called the network coordinator. End stations work in function reduced functionality device (RFD). They have limited function with regard to the router or to alone coordinator nevertheless, their big advantage is in introducing the sleep; mode with decreased power consumption (current consumption about $2.6 \mu \mathrm{A}$ ). Temperature, rel. humidity, lighting, and amount of carbon monoxide $\mathrm{CO}$ (sensor DrägerSensor CO-6809605) belong among measured values. The whole system may bring relevant information about the status, pollution rate, and living condition of residents of the industrial cities such as Ostrava.

\section{Conclusions}

This paper introduces evolving segment of optimized power supply for wireless sensors. Due to the use of a very lowpower sensor based on IEEE 802.15.4 standard, it is not possible to operate complete wireless solution for long time powered only by the battery. Current available commercial solutions for charging circuit are, however, not designed for changeable weather condition, when sun light is not at high intensity. Designed charging circuit (voltage regulator) is 
a result of used components which are able to work with solar panel supplying lower output voltage. The designed solution of DC-DC converter power supplying wireless module has a good efficiency compared to other commercial circuits and also it is less costly. The developed solution covers design of a solar panel as well as all charging circuits of power supply. It is possible to apply the solution from lower voltage (lower sun intensity) which results in better reliability of operation. A number of specific tests were performed with Jennic JN5139 modules on the created Jeanie Network [15].

The developed functional unit of power supply allows the wireless module to work outdoors for a time which is limited only by lifetime of used individual components. This fact is very important, due to the high servicing period of remote measurement nodes which lower spending of money for consequent maintaining.

\section{Acknowledgments}

This paper was partially supported by the project (1) "Smart Solutions in Ubiquitous Computing Network Environments," Grant Agency of Excellence, University of Hradec Kralove, Faculty of Informatics and Management; (2) "SMEW-Smart Environments at Workplaces" Grant Agency of the Czech Republic, GACR P403/10/1310; (3) the framework of the project Opportunity for young researchers, Registiration no. CZ.1.07/2.3.00/30.0016, supported by Operational Programme Education for Competitiveness and cofinanced by the European Social Fund and the state budget of the Czech Republic. The authors also acknowledge support from Cautum Company (http://cautum.cz/). Last but not least, the authors acknowledge the technical language assistance provided by Stanislava Horakova (University of Warwick).

\section{References}

[1] M. Cerny and M. Penhaker, "Wireless body sensor network in health maintenance systems," Electronics and Electrical Engineering, vol. 115, no. 9, pp. 113-116, 2011.

[2] N. Chilamkurti, S. Zeadally, and F. Mentiplay, "Green networking for major components of information communication technology systems," Eurasip Journal on Wireless Communications and Networking, vol. 2009, Article ID 656785, 7 pages, 2009.

[3] "Wind power plant in Pchery," 2012 http://www.vtepchery.cz/ projekt.html.

[4] V. Raghunathan, A. Kansal, J. Hsu, J. Friedman, and M. Srivastava, "Design considerations for solar energy harvesting wireless embedded systems," in Proceedings of the 4th International Symposium on Information Processing in Sensor Networks (IPSN '05), pp. 457-462, IEEE Press, Piscataway, NJ, USA, April 2005.

[5] R. Morais, M. A. Fernandes, S. G. Matos, C. Serôdio, P. J. S. G. Ferreira, and M. J. C. S. Reis, "A ZigBee multi-powered wireless acquisition device for remote sensing applications in precision viticulture," Computers and Electronics in Agriculture, vol. 62, no. 2, pp. 94-106, 2008.

[6] M. Di Francesco, G. Anastasi, M. Conti, S. K. Das, and V. Neri, "Reliability and energy-efficiency in IEEE 802.15.4/ZigBee sensor networks: an adaptive and cross-layer approach," IEEE
Journal on Selected Areas in Communications, vol. 29, no. 8, Article ID 5992822, pp. 1508-1524, 2011.

[7] J. Pelegri-Sebastia, R. L. Vizcaino, and J. A. Lluch, "Solar power source for autonomous sensors," in Renewable Energy, T. J. Hammons, Ed., InTech, 2009, http://www.intechopen.com/ http://www.intechopen.com/books/renewable-energy/solarpower-source-for-autonomous-sensors.

[8] X. Jiang, J. Polastre, and D. Culler, "Perpetual environmentally powered sensor networks," in Proceedings of the 4th International Symposium on Information Processing in Sensor Networks, IPSN 2005, pp. 463-468, IEEE Press, Piscataway, NJ, USA, April 2005.

[9] A. Tofighi and M. Kalantar, "Power management of PV/battery hybrid power source via passivity-based control," Renewable Energy, vol. 36, no. 9, pp. 2440-2450, 2011.

[10] M. Kalantar and S. M. Mousavi, "Dynamic behavior of a stand-alone hybrid power generation system of wind turbine, microturbine, solar array and battery storage," Applied Energy, vol. 87, no. 10, pp. 3051-3064, 2010.

[11] A. Tofighi and M. Kalantar, "Adaptive passivity-based control of PEM fuel cell/battery hybrid power source for standalone applications," Advances in Electrical and Computer Engineering, vol. 10, no. 4, pp. 111-120, 2010.

[12] S. Rehman, M. A. Bader, and S. A. Al-Moallem, "Cost of solar energy generated using PV panels," Renewable and Sustainable Energy Reviews, vol. 11, no. 8, pp. 1843-1857, 2007.

[13] M. Tutsch, P. Vojcinak, J. Koziorek, and M. Skrepek, "Using automated evaluation of efficiency for photovoltaic power plant," in Proceedings of the IEEE 16th Conference on Emerging Technologies and Factory Automation (ETFA '11), pp. 1-4, Toulouse, France, 2011.

[14] "LTC3531-3 DC-DC converter datasheet," http://cds.linear .com/docs/Datasheet/3531fb.pdf.

[15] L. Smutný, M. Mahdal, and J. Škuta, "Smart sensors with PC connection in wireless networks," in Proceedings of the 13th WSEAS International Conference on Computers, pp. 585-587, WSEAS Press, July 2009. 


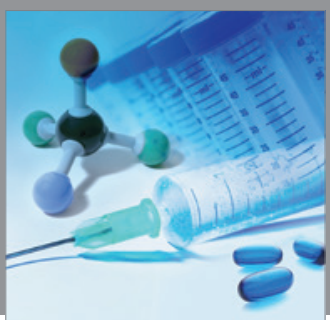

International Journal of

Medicinal Chemistry

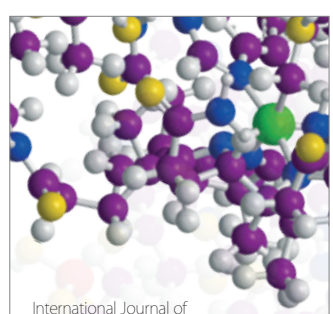

Carbohydrate Chemistry

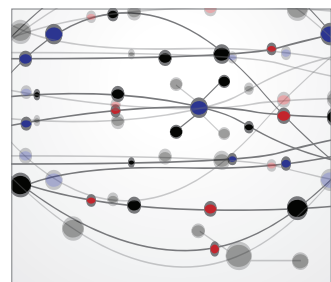

The Scientific World Journal
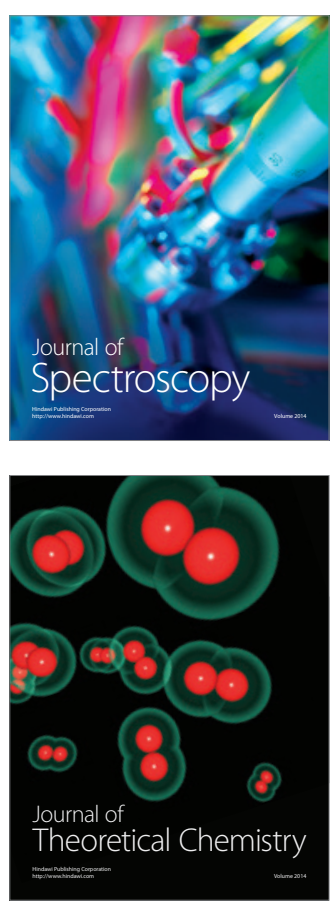
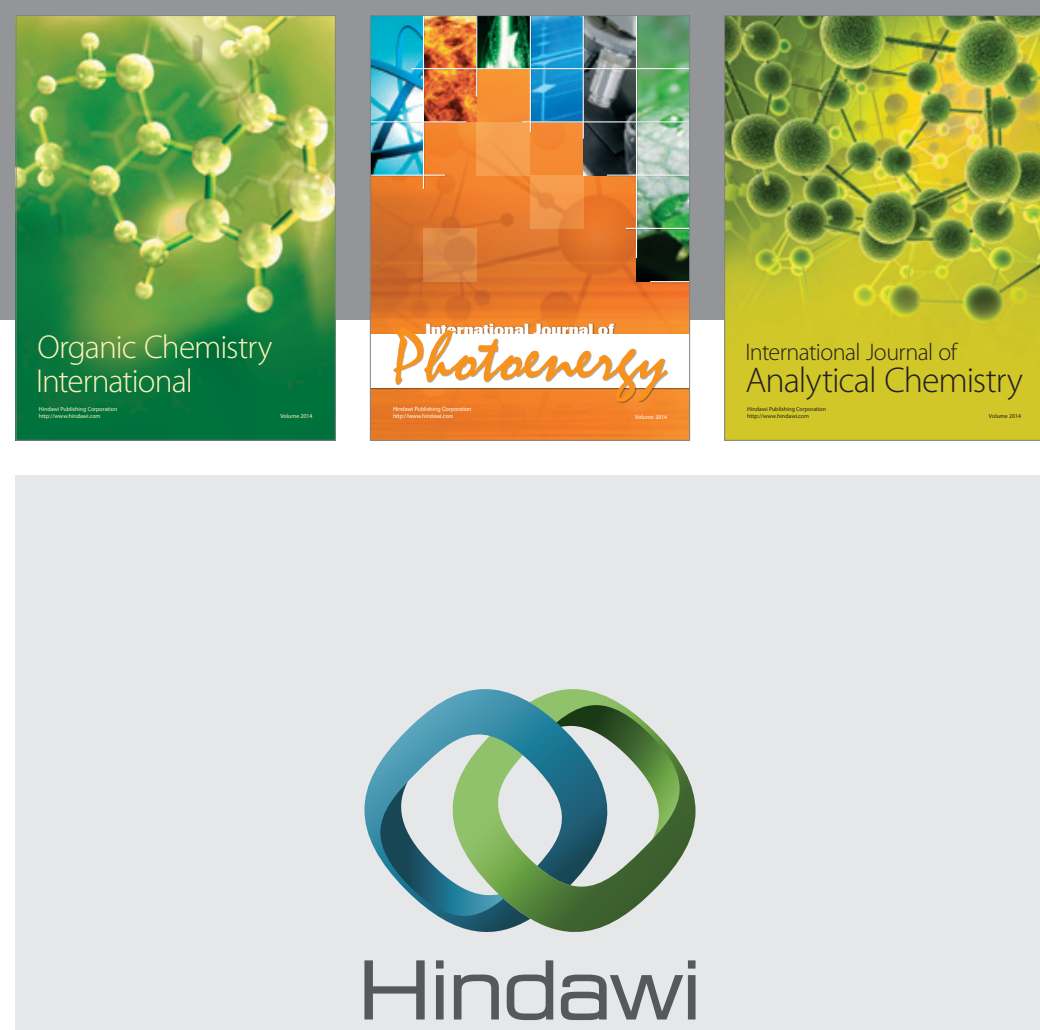

Submit your manuscripts at

http://www.hindawi.com
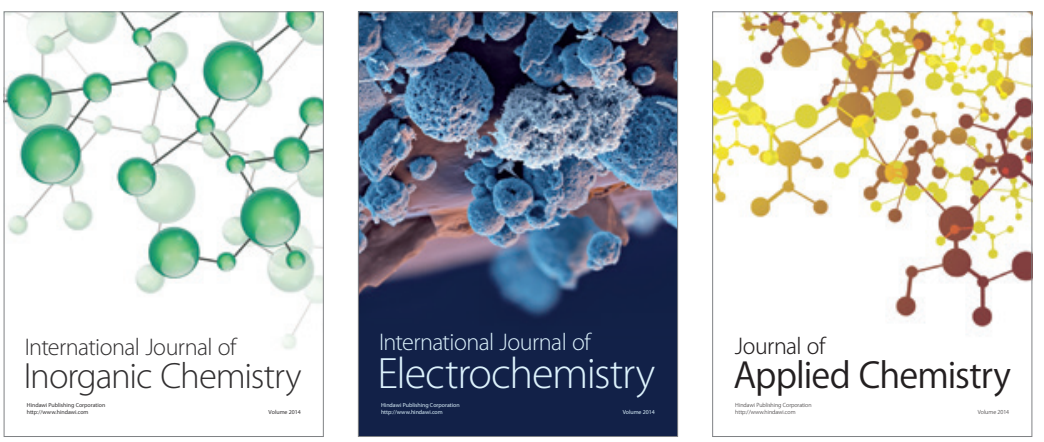

Journal of

Applied Chemistry
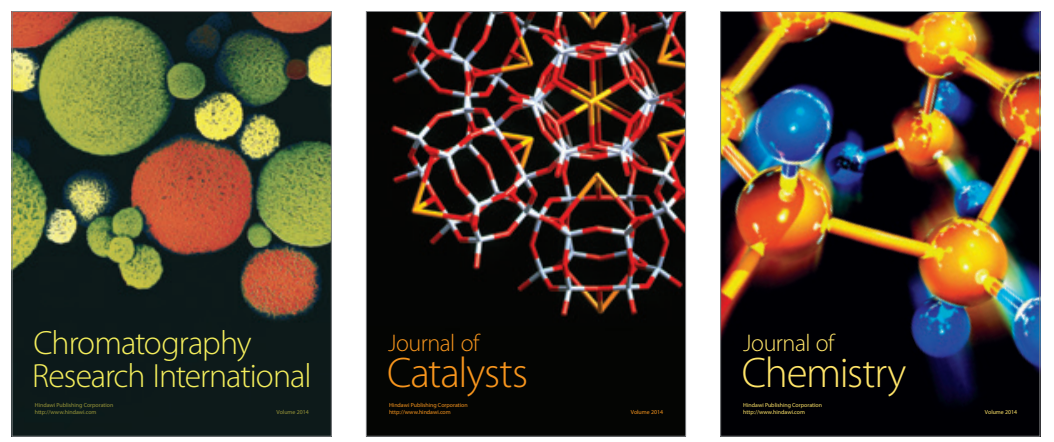
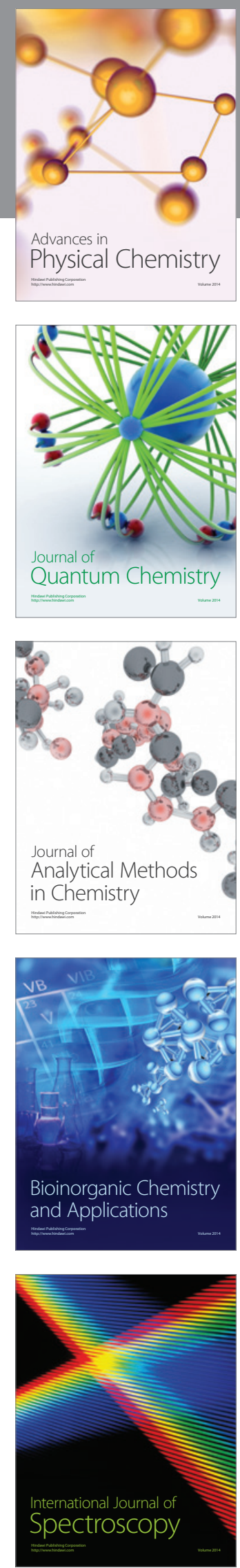